\title{
Palaeoecological and Palaeoclimatical Reconstructions of Holocene According Chironomid Analysis of Lake Glubokoye Sediments ${ }^{1}$
}

\author{
L. B. Nazarova ${ }^{a, b}$, T. V. Sapelko ${ }^{c, d}$, D. D. Kuznetsov ${ }^{c, d}$, and L. S. Syrykh ${ }^{c, d}$ \\ Presented by Academician Yu.Yu. Dgebuadze September 1, 2014
}

Received September 23, 2014

DOI: $10.1134 / \mathrm{S} 0012496615010172$

Climate change is one of the most widely discussed subjects in science and society today. Among different studies of climate variability, palaeoreconstructions are of a special importance, because they allow climatic changes to be traced over long periods of time. Natural "archives" (lake sediments, soils, ice, etc.) still remain a valuable source of information on the climate development in remote historical past. In this regard, palaeoclimatic studies aimed at obtaining not only detailed qualitative reconstructions of the past environmental conditions, but, more importantly, quantitatively reconstructing of the climate are of a particular importance as part of identification of historical trends in the development of Earth's climate and validation of global climatic models.

The use of remains of chironomid head capsules preserved in lake sediments is increasingly popular in paleoclimatology [1]. Chitinous head capsules of chironomids are usually numerous in lake sediments and readily identifiable. Due to cosmopolitan distribution, which is limited globally by the air temperature, chironomids are among the best indicators of the climate changes [2] and have significant potential for the assessment of the other environmental changes.

However, all quantitative reconstructions using biological indicators, including chironomids, are

\footnotetext{
${ }^{1}$ The article was translated by the authors.

${ }^{a}$ Alfred Wegener Institute, Helmholtz Centre for Polar and Marine Research, Potsdam, Germany

${ }^{b}$ Kazan Federal University, Kazan, Tatarstan, Russia

${ }^{c}$ Institute of Limnology, Russian Academy of Sciences, St. Petersburg, Russia

${ }^{d}$ Herzen State Pedagogical University of Russia,

St. Petersburg, Russia;

e-mail: tsapelko@mail.ru
}

based on empirical statistical models developed on the basis of the regional calibration datasets.

Over the past decades, it has been shown that, among other climatic factors, mean July air temperature is most significantly correlated with the distribution of chironomids. Regional databases lead to development of the statistical models for the reconstruction of the mean July air temperature that are widely used in northern Europe and North America [3-6]. More recently, similar models have been used in Russia [7, 8], leading to obtaining highly accurate reconstructions of palaeoclimate $[9,10]$. Such a study for Central Russia has been carried out for the first time.

The aim of our study was to conduct a quantitative reconstruction of the mean July air temperature and palaeoecological conditions of the Holocene in Central Russia from the sediment core of Lake Glubokoye using chironomids (Diptera: Chironomidae) as bioproxy.

Lake Glubokoye (Ruza raion, Moscow oblast) has a rounded shape; the lake area is $0.59 \mathrm{~km}^{2}$ with a maximum depth of $32 \mathrm{~m}$. The lake has one outflow, the Malaya Istra River. A sediment core was recovered from the ice $\left(55^{\circ} 45^{\prime} 537^{\prime} \mathrm{N}, 36^{\circ} 30^{\prime} 472^{\prime \prime} \mathrm{E}\right)$ in a bay in the northern part of the lake (a small basin) from a depth of $3.3 \mathrm{~m}$. The total length of the core was $4 \mathrm{~m}$.

According to radiocarbon analysis, the core covers the the Late Glacial and the whole Holocene [11]. The whole sediment core was sampled for chironomid analysis. Samples were processed according to a standard method [2]. Identification was performed using a modern specialized identification manual [12] and national collection of chironomids from the Natural History Museum, London, United Kingdom.

Stratigraphic diagram was made in $\mathrm{C} 2$ (figure). Horizons $649-728 \mathrm{~cm}$ and $503-560 \mathrm{~cm}$ were either empty or contained too few head capsules and, therefore, were not included in the statistical analysis. Prin- 


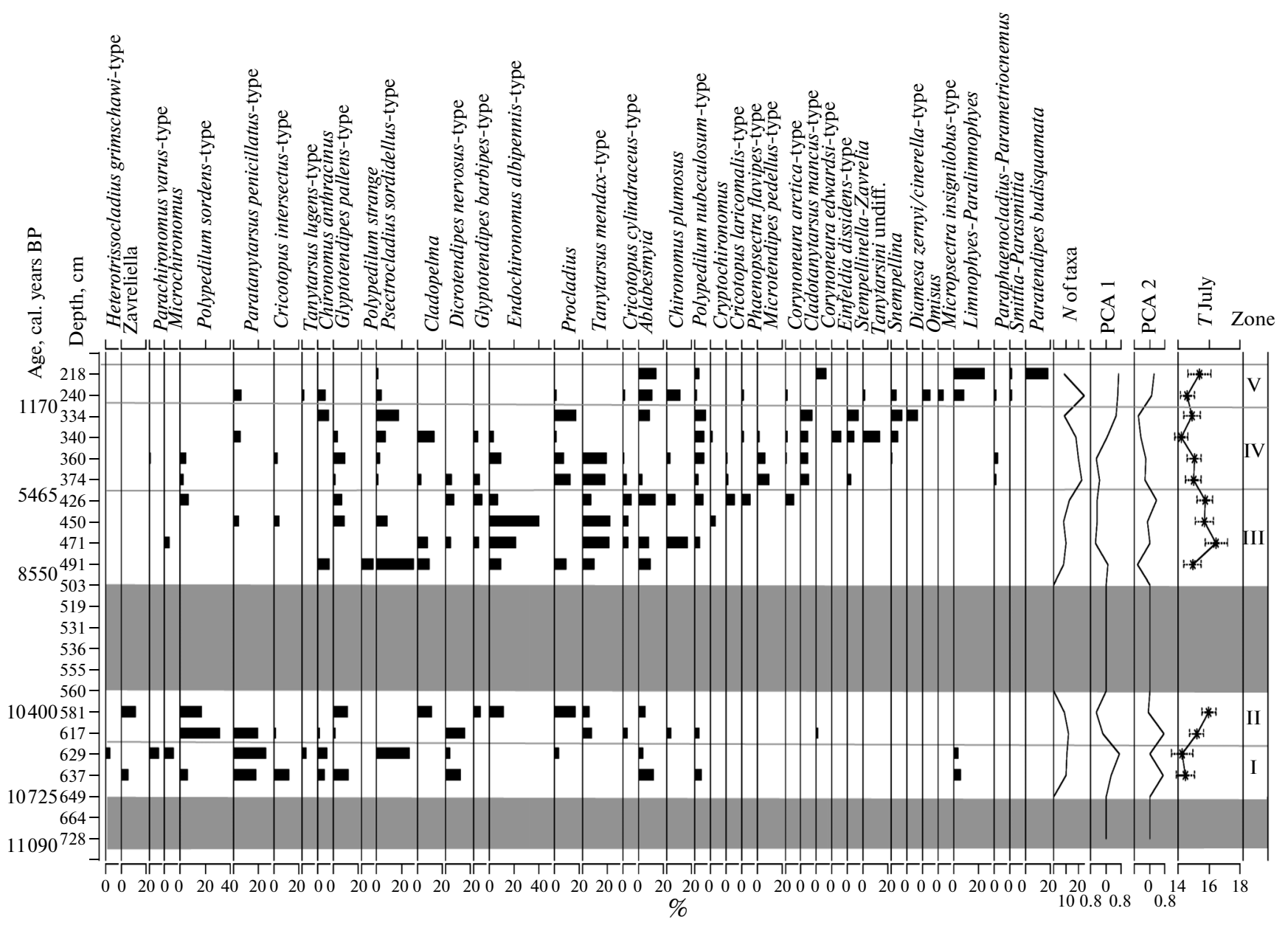

Stratigraphic distribution of chironomid taxa of Lake Glubokoye sediments and mean July air temperature reconstructed with the use of the Russian chironomid statistical model.

cipal component analysis (PCA) was used to study the general trends in species composition. Reconstruction of the mean July temperature (T July) was done using the Russian chironomid model [8].

Using BSTICK ZONE software [13] and PCA axes 1 and 2, we distinguished five statistically significant zones in the sediment core.

Zones I-II: Horizons 581-637 cm (1072510400 cal. years BP). Taxonomic diversity of the chironomid communities is low. The number of taxa in the samples varies from 9 to 12 . The dominant complex includes taxa associated with aquatic vegetation, indicating moderate or cool temperature conditions (Paratanytarsus penicillatus-type, Polypedilum sordens-type, Dicrotendipes nervosus-type, Zavreliellatype). In Zone I, a fairly high number of Limnophies is found. This taxon is primarily associated with shallow waters and is an indicator of an unstable water level. The dominant taxa in this zone are Paratanytarsus penicillatus-type and Psectrocladius sordidellus-type.
Zone II is dominated by Polypedilum sordens-type, Procladius-type, and Zavreliella-type.

Reconstructed conditions: $\mathrm{T}$ July is lower than today (reconstructed $\mathrm{T}$ July are $14.6 \pm 1.2^{\circ} \mathrm{C}$ ); the presence of shallow, probably boggy areas. By the end of the zone, the temperature slightly increases, but it does not reach the modern level (reconstructed T July are 15.4 to $16.3 \pm 1.2^{\circ} \mathrm{C}$ ), trophicity increases, the water level may decrease.

The resulting reconstruction is consistent with the previous results, according to which the given period was relatively cool, an accumulation of mineral sediments took place, and the lake water was oligotrophic [14].

The absence or very low concentration of chironomid head capsules at the depths of $581-503 \mathrm{~cm}$ (10 400-8550 cal. years BP), as well as indistinct stratification and the presence of mineral material with some ostracods inclusions in sediments [11], indicate lowering of the lake level. During this period, the northern basin, where the sediment core was taken 
could become shallow or even could be a subjected to drying, which made the conditions impossible for development of chironomid fauna here.

Zone III: Horizons 426-503 cm (8550-5465 cal. years BP). The number of chironomid taxa gradually increases. The most abundant taxa are phytophilic mesotrophic and eutrophic, aquatic vegetation miners Endochironomus albipennis-type, Tanytarsus mendaxtype, Ablabesmyia. Endochironomus albipennis. In the upper horizons abundance of acidophilic taxa (Ablabesmyia, Glyptotendipes pallens-type) increases.

Reconstructed conditions: T July rises and reaches the modern level (average temperature $=16 \pm 1.2^{\circ} \mathrm{C}$, the $\mathrm{T}$ July vary from 15 to $17 \pm 1.2^{\circ} \mathrm{C}$ ). Trophicity increases, submerged aquatic vegetation is widely represented. The presence of acidophilic taxa indicates strengthening of the processes of paludification in the lake.

Zone IV: Horizons 334-240 cm (5465-1170 cal. years BP). The average number of taxa in a sample increases to 18. Polypedilum nubeculosum-type, Cladotanytarsus mancus-type, and Procladius indicative of temperate, littoral, and eutrophic conditions, respectively, are abundant throughout the zone. The abundance of the phytophilic Paratanytarsus penicillatus-type gradually increases. Stempellina and Stempellinella-Zavrelia, apart from lakes, are often found in streams and small rivers.

Reconstructed conditions: trophicity and the density of riparian vegetation increase, the reconstructed temperatures indicate some cooling ( $\mathrm{T}$ July is $15 \pm$ $1.2^{\circ} \mathrm{C}$, the temperature variations are between 14.5 and $15.3 \pm 1.2^{\circ} \mathrm{C}$ ). The presence of fluvial taxa indicates an increase in flow and rise of the water level in the lake and indirectly indicates general humidification of the climate, which is consistent with the results of other analyses $[11,14]$.

Zone V. Horizons 218-240 cm (after 1170 cal. years BP). The beginning of the zone has the richest taxonomic diversity, where 25 taxa were found. However, in the upper horizon, the number of the taxa decreases to 9. The characteristic feature of this zone is the high number of Limnophyes-Paralimnophyes, a taxon that is mainly associated with shoals and macrophytes and is an indicator of an unstable water level.

This zone contains other species indicative of shallow-water conditions, Smittia and Paraphaenocladius. The emergence of Smittia suggests erosion processes. Corynoneura edwardsi-type is common in lake sediments of the littoral zone under mild climatic conditions. It lives among macrophytes and floating plants. Paratendipes budisquamata is mainly indicative of littoral conditions of mesotrophic lakes, but sometimes occurs in flowing waters. Ablabesmyia is a phytophilic, eutrophic, and practically ubiquitous taxa associated with acidified ponds. Micropsectra insignilobus-type and Omisus were found in smaller quantities, but only within this zone. Both taxa are characteristic of water bodies with low trophicity. Reconstructed conditions: expansion of shoals with lots of aquatic vegetation, mild acidification, lowering of the lake trophicity along with the rise of the water level.

Reconstructed T July is similar to that in the previous zone $\left(14.8\right.$ to $\left.15.5 \pm 1.2^{\circ} \mathrm{C}\right)$. July temperature of the upper horizon is higher than that of the lower horizons of this zone and is close to the modern one $\left(16.4 \pm 1.2^{\circ} \mathrm{C}\right)$.

Thus, this study using the first Russian statistical chironomid temperature model has provided the first reconstruction of the Holocene temperatures for Central Russia, which has given a new quantitative information on development of paleoclimate in the central part of the East European Plain.

It has been shown that, during the Early Holocene, in the Moscow region, the mean July temperatures were below the modern level and varied between 14.6 and $16.3^{\circ} \mathrm{C}$; t during the Middle Holocene (54651170 cal. years BP), July temperatures increased, ranging from 15 to $17^{\circ} \mathrm{C}$; during the Late Holocene (after 5500 cal. years BP), the reconstructed temperatures indicate some cooling, with July temperature varying between 14.5 and $15.3^{\circ} \mathrm{C}$.

In addition, using the taxonomic composition of chironomid communities, we reconstructed changes in the ecological system of the Lake Glubokoye. It was shown that during the Early Holocene a gradual increase in the lake trophicity was followed by a possible lowering of the lake water level. During the Middle Holocene, the revealed earlier trend of the rise of the lake trophicity was accompanied by the processes of paludification of the lake and a wide spreading of submerged aquatic vegetation. In the Late Holocene, the appearance of the fluvial taxa indicates an increase in flow in the lake and, indirectly, a general humidification of climate, which is consistent with the results of other analyses.

\section{ACKNOWLEDGMENTS}

We are extremely grateful to all stuff members of the hydrobiological station "Lake Glubokoe," especially to its scientific supervisor, professor Nikolay Nikolaevich Smirnov. The study was supported by the Russian Foundation for Basic Research (project no. 14-04-01569_a), an OSL grant, and the Russian Government Program for Increasing the Competitiveness of Kazan Federal University.

\section{REFERENCES}

1. Self, A.E., Brooks, S.J., Birks, H.J.B., Nazarova, L., et al., Quatern. Sci. Rev., 2011, vol. 30, pp. 1122-1141. 
2. Brooks, S.J. and Birks, H.J.B., Quatern. Sci. Rev., 2001, vol. 20, pp. 1723-1741.

3. Larocque, I., Hall, R.I., and Grahn, E., J. Paleolimnol., 2001, vol. 26, pp. 307-322.

4. Barley, E.M., Walker, I.R., Kurek, J., Cwynar, L.C., et al., J. Paleolimnol., 2006, vol. 36, pp. 295-314.

5. Dieffenbacher-Krall, A.C., Vandergoes, M.J., and Denton, G.H., Quatern. Sci. Rev., 2007, vol. 26, pp. 2487-2504.

6. Gajewski, K., Bouchard, G., Wilson, S.E., Kurek, J., and Cwynar, L.C., Hydrobiologia, 2005, vol. 549, pp. 131-143.

7. Nazarova, L.B., Pestryakova, L.A., Ushnitskaya, L., and Hubberten, H.W., Contemp. Probl. Ecol., 2008, vol. 1, pp. 335-345.

8. Nazarova, L., Herzschuh, U., Wetterich, S., Kumke, Th., and Pestjakova, L., J. Palaeolimnol., 2011, vol. 45, pp. 57-71.
9. Nazarova, L., de Hoog, V., Hoff, U., and Diekmann, B., Quatern. Sci. Rev., 2013, vol. 67, pp. 81-92.

10. Ilyashuk, E.A., Ilyashuk, B.P., Hammarlund, D., and Larocque, I., Holocene, 2005, vol. 15, no. 6, pp. 897914.

11. Sapelko, T.V., Smirnov, N.N., Shcherochin'ska, K., Khasanov, B., et al., Dokl. Akad. Nauk, 2013, vol. 450, no. 3, pp. 344-347.

12. Brooks, S.J., Langdon, P.G., and Heiri, O., Using and Identifying Chironomid Larvae in Palaeoecology: $Q R A$ Technical Guide no. 10, London: Quatern. Res. Assoc., 2007.

13. Lotter, A.F. and Juggins, S., Newsletter, 1991, vol. 6, pp. 4-6.

14. Sapelko, T., Antipushina, Z., and Ludikova, A., in Paleoecological reconstructions-Lacustrine, Peat and Cave Sediments (Abstr. Conf.), Białka Tatrzańska, 2013, pp. 36-37. 